OLIVEIRA CM; CONEGLIAN RCC; CARMO MGF. 2015. Conservação pós-colheita de tomate cereja revestidos com película de fécula de mandioca. Horticultura Brasileira 33: 471-479. DOI - http://dx.doi.org/10.1590/S0102-053620150000400011

\title{
Conservação pós-colheita de tomate cereja revestidos com película de fécula de mandioca
}

\author{
Cristiana M Oliveira; Regina CC Coneglian; Margarida GF Carmo \\ Universidade Federal Rural do Rio de Janeiro (UFRRJ), Seropédica-RJ, Brasil; cristiana.maia@hotmail.com; rccconeg@ufrrj.br; \\ gorete@ufrrj.br
}

\section{RESUMO}

O tomate após a colheita apresenta-se como um fruto altamente perecível. Por ser um fruto climatérico, seu amadurecimento acarreta uma série de transformações em suas características físicas e químicas. Diante disso, o objetivo do trabalho foi avaliar a longevidade e qualidade pós-colheita de tomate cereja após a aplicação de película de fécula de mandioca sob condições ambiente e controlada. Foram utilizados frutos de duas cultivares, Perinha Água Branca e Mascot, colhidos na maturação fisiológica. Os tratamentos utilizados foram $0 \%, 1 \%, 3 \%$ e $5 \%$ de fécula de mandioca seguidos de avaliações aos $0,4,8,12,16,20$ e 24 dias de armazenamento, em dois ensaios distintos: um sob temperatura ambiente $\left(25 \pm 2^{\circ} \mathrm{C}\right)$ e outro sob condições controladas $\left(12^{\circ} \mathrm{C}\right.$ e UR $\left.90 \%\right)$. O delineamento experimental adotado foi inteiramente casualizado em esquema fatorial $2 \times 4 \times 7 \mathrm{com}$ três repetições de 8 frutos por embalagem. As avaliações realizadas foram perda de massa fresca, acidez titulável, sólidos solúveis, atividade de pectinametilesterase (PME) e relação sólidos solúveis com acidez titulável. Em temperatura ambiente, a perda de massa fresca em 'Mascot' foi maior em frutos revestidos com féculas 3\% e 5\%. Estas concentrações proporcionaram menor atividade de PME. Em temperatura controlada a acidez titulável foi menor para revestimento de 3\% e 5\% em 'Mascot' e 'Perinha'. O revestimento de fécula 5\% proporcionou baixa longevidade pós-colheita e fécula $1 \%$ se assemelhou ao controle em ambas as condições avaliadas. O revestimento de frutos com fécula $3 \%$ preservou parâmetros de qualidade como menor acidez e menor atividade de PME sendo considerado o mais eficaz.

Palavras-chave: Solanum lycopersicum, revestimento comestível, longevidade pós-colheita.

\begin{abstract}
Postharvest conservation of cherry tomato fruits coated with cassava starch film

Tomato is a highly perishable fruit. As a climacteric fruit, the ripening process involves a series of changes in its physical and chemical characteristics. Thus, the main goal of this study was to evaluate the longevity and postharvest quality of cherry tomato fruits after applying cassava starch film under room and controlled temperature conditions. Cultivars 'Perinha Água Branca' and 'Mascot' were harvested at physiological maturity and used in this study. Cassava starch was applied at $0 \%, 1 \%, 3 \%$ and $5 \%$ followed by assessments at $0,4,8,12,16,20$ and 24 days in two separate trials: one under room temperature $\left(25 \pm 2^{\circ} \mathrm{C}\right)$ and the other under controlled condition $\left(12^{\circ} \mathrm{C}\right.$ and $\left.90 \% \mathrm{RH}\right)$. The experimental design was completely randomized, with three replications containing 8 fruits per package in a $2 \times 4 \times 7$ factorial. Fresh weight loss, titratable acidity, soluble solids, pectinmethylesterase activity (PME) and the relation between soluble solids and titratable acidity were evaluated. Weight loss of 'Mascot' was higher in fruit coated with 3\% and $5 \%$ of starch, at room temperature and a lower PME activity was observed. Acidity was lower at 3\% and 5\% in 'Mascot' and 'Perinha' at controlled temperature. The treatment at $5 \%$ provided the lowest postharvest longevity, whereas the treatment at $1 \%$ was similar to control in both conditions evaluated. The treatment at $3 \%$ preserved quality parameters such as lower acidity and lower PME activity and was considered the most effective treatment.
\end{abstract}

Keywords: Solanum lycopersicum, edible coating, postharvest longevity.

(Recebido para publicação em 22 de maio de 2014; aceito em 12 de maio de 2015) (Received on May 22, 2014; accepted on May 12, 2015)

$\mathrm{O}$ Brasil é o oitavo maior produtor de tomate no mundo com produção de 4.146,466 mil toneladas, em uma área colhida de 66.221 ha (IBGE, 2012).

Dois terços do tomate comercializado no Brasil são destinados ao consumo in natura, por isso o aspecto externo e a qualidade do fruto são fatores de suma importância que influenciam diretamente na decisão de compra pelo consumidor (Casa \& Evangelista, 2009).

Durante o período pós-colheita, o tomate, por ser climatérico, tem suas transformações físicas e químicas acentuadas à medida que aumenta a temperatura na qual os frutos estão expostos. Essas transformações são decorrentes de alterações fisiológicas e bioquímicas, identificadas pelos fatores de qualidade como perda de massa, peso específico, sólidos solúveis, $\mathrm{pH}$, acidez, açúcares solúveis e vitamina C (Ferreira, 2004). Por isso, algumas técnicas são utilizadas visando aumentar a vida útil. Entre elas pode-se citar o aumento da umidade relativa do ar, diminuição da temperatura, uso de embalagens e atmosfera modificada (AM), como por exemplo, revestimentos comestíveis (Lemos et al., 2008). 
Segundo Gallo et al. (2000), os revestimentos comestíveis podem ter como base polissacarídeos (derivados de amido, pectina, alginatos, etc.), proteínas (isoladas de soja ou do soro de leite, etc.) e lipídios (ao qual se incluem ceras, óleos hidrogenados, triglicerídeos, entre outros).

O revestimento a partir de fécula de mandioca, material constituído por polissacarídeo, apresenta como características a formação de películas resistentes e transparentes, eficientes barreiras à perda de água, bom aspecto e brilho intenso, o que torna os frutos e hortaliças comercialmente atrativos (Cereda et al., 1992; Vila, 2004).

Alguns estudos foram realizados tendo por objetivo avaliar a viabilidade do uso de película de fécula de mandioca em diferentes concentrações em frutas e hortaliças. Castricini (2009) obteve resultados positivos com revestimentos à base de fécula de mandioca nas concentrações de 3 e $5 \%$ em mamões 'Golden', em que se reduziram a perda de massa, mantiveram a coloração verde durante o armazenamento e proporcionaram maior firmeza.

Damasceno et al. (2003) avaliaram a aplicação de suspensões a 2 e $3 \%$ de fécula de mandioca em tomate, verificando que as películas formadas não influenciaram na perda de massa e na textura. Entretanto os frutos revestidos com películas formadas pela suspensão a 3\% apresentaram melhor aparência.

Resultados poucos expressivos ou negativos também são relatados. Souza et al. (2009) verificaram que berinjelas revestidas por fécula tiveram a aparência externa afetada com perda de brilho, sintomas de murcha, depressões na casca, ataque de fungos além de descascamento da película. Em trabalho realizado por Lemos et al. (2008), a fécula de mandioca associada à refrigeração em pimentão não formou eficiente barreira à perda de massa fresca.

Neste contexto, este trabalho teve por objetivo avaliar a longevidade e qualidade pós-colheita de tomate cereja após a aplicação de película de fécula de mandioca sob condições ambiente e controlada.

\section{MATERIAL E MÉTODOS}

Foram utilizados tomate cereja das cultivares Perinha Água Branca e do híbrido Mascot obtidos em plantio conduzido sob manejo orgânico no período de junho a outubro de 2012 no setor de Horticultura do Departamento de Fitotecnia da Universidade Federal Rural do Rio de Janeiro (UFRRJ), localizado em Seropédica-RJ. Após a colheita, estes foram conduzidos ao Laboratório de Pós-Colheita do Departamento de Fitotecnia da UFRRJ, onde foram selecionados, lavados em solução clorada e uniformizados quanto ao grau de maturação "de vez", baseando-se nos estádios de maturação descritos por Brasil (1995), na qual frutos de vez são caracterizados pela presença das cores amarela, rosa ou vermelho entre 10 e $30 \%$ da superfície do fruto. Após esta etapa foram aplicados os tratamentos revestidos constituídos de três concentrações de fécula de mandioca, $1,3 \mathrm{e}$ $5 \%$, mais um tratamento controle $(0 \%$ de fécula de mandioca). Em seguida, os frutos foram acondicionados em embalagens plásticas com 8 furos na superfície, para permitir a troca de gases com o ambiente, e armazenados por 0 , $4,8,12,16,20$ e 24 dias, sob condição ambiente $\left(25 \pm 2^{\circ} \mathrm{C}\right)$ e sob condições controladas $\left(12^{\circ} \mathrm{C}\right.$ e UR $\left.90 \%\right)$.

As formulações foram obtidas por meio de aquecimento sob agitação da fécula de mandioca em água. Estas foram aquecidas à temperatura máxima de $70^{\circ} \mathrm{C}$, com agitação constante, até a geleificação da fécula. As suspensões foram preparadas no dia anterior à colheita dos frutos, para a aplicação fria e após a dissipação das bolhas que a agitação provoca. Os frutos foram imersos nessas suspensões e colocados para secar sobre tela de "nylon" a fim de drenar o excesso de suspensão, de acordo com Henrique (1999).

Ao final de cada um dos sete períodos de armazenamento avaliaram-se as características físicas e químicas a seguir: Perda de massa fresca obtida pela diferença entre a massa inicial dos frutos e a massa final em cada dia de avaliação, por meio de pesagem em balança digital, sendo os resultados expressos em porcentagem. Acidez titulável obtida utilizando-se $10 \mathrm{~g}$ da amostra diluída em $100 \mathrm{~mL}$ de água destilada sob agitação moderada. Essa solução foi titulada com $\mathrm{NaOH} 0,1 \mathrm{~N}$ até a faixa de $\mathrm{pH} 8,2$ a 8,4 (IAL, 1987). O resultado foi expresso em mg de ácido cítrico/100 g de polpa. Sólidos solúveis determinado por leitura direta em refratômetro manual, com resultados expressos em ${ }^{\circ}$ Brix (IAL, 1987). Relação sólidos solúveis pela acidez titulável (SS/AT) obtida pela razão entre os teores de sólidos solúveis e de acidez titulável. Pectinametilesterase (PME) determinada segundo Hultin et al. (1966) e Ratner et al. (1969). Obteve-se o extrato enzimático homogeneizando $10 \mathrm{~g}$ de polpa de tomate com $20 \mathrm{~mL}$ de $\mathrm{NaCl} 0,2 \mathrm{~N}$ (gelado), em “mixer". Quatro mililitros de extrato enzimático foram adicionados sobre $30 \mathrm{~mL}$ de pectina cítrica a $1 \% \mathrm{em}$ $\mathrm{NaCl} 0,2 \mathrm{~N}$. O pH da solução foi mantido em torno de 7,0 por dez minutos, com $\mathrm{NaOH} 0,01 \mathrm{~N}$ (titulação) e uma unidade de PME foi definida como a quantidade de enzima capaz de catalisar a desmetilação de pectina correspondente ao consumo de $1 \mu \mathrm{mol}$ de $\mathrm{NaOH} / \mathrm{min} / \mathrm{g}$ de massa fresca, nas condições de ensaio, expressa em $\mathrm{U} / \mathrm{g} / \mathrm{min}$.

O delineamento experimental foi inteiramente casualizado em esquema fatorial $2 \times 4 \times 7$ (duas cultivares, quatro tratamentos e sete períodos de armazenamento), para cada uma das duas condições de ambiente. Utilizaram-se três repetições sendo cada parcela composta por uma embalagem com oito frutos.

Em cada um dos dois ensaios, os dados foram submetidos à análise de variância e as médias comparadas pelo teste de Tukey a $5 \%$ para aferir o efeito dos tratamentos (cultivar e revestimento), utilizando-se o programa SISVAR na realização das análises estatísticas. A regressão foi realizada para aferir o efeito das concentrações de fécula no fruto em função do tempo de armazenamento. $\mathrm{Na}$ análise de regressão, testaram-se o modelo linear e de segundo grau. Alguns tratamentos tiveram menor vida útil $\mathrm{e}$, portanto, menor período de armazenamento. 
RESULTADOS E DISCUSSÃO

Armazenamento em temperatura ambiente $\left(25^{\circ} \mathrm{C} \pm 2^{\circ} \mathrm{C}\right)$ - As avaliações pós-colheita dos frutos de 'Perinha Água
Branca' foram realizadas somente até o $20^{\circ}$ dia para o controle e revestimentos de fécula 1 e $3 \%$ e no tratamento com fécula $5 \%$ até o $12^{\circ}$ dia devido ao aparecimento de podridões. Já para os frutos de 'Mascot', as análises prosseguiram até o $24^{\circ}$ dia para o controle, fécula 1 e $3 \%$, enquanto que para fécula $5 \%$ estas foram realizadas até o $16^{\circ}$ dia. A avaliação aos 4 dias da cv. Mascot foi
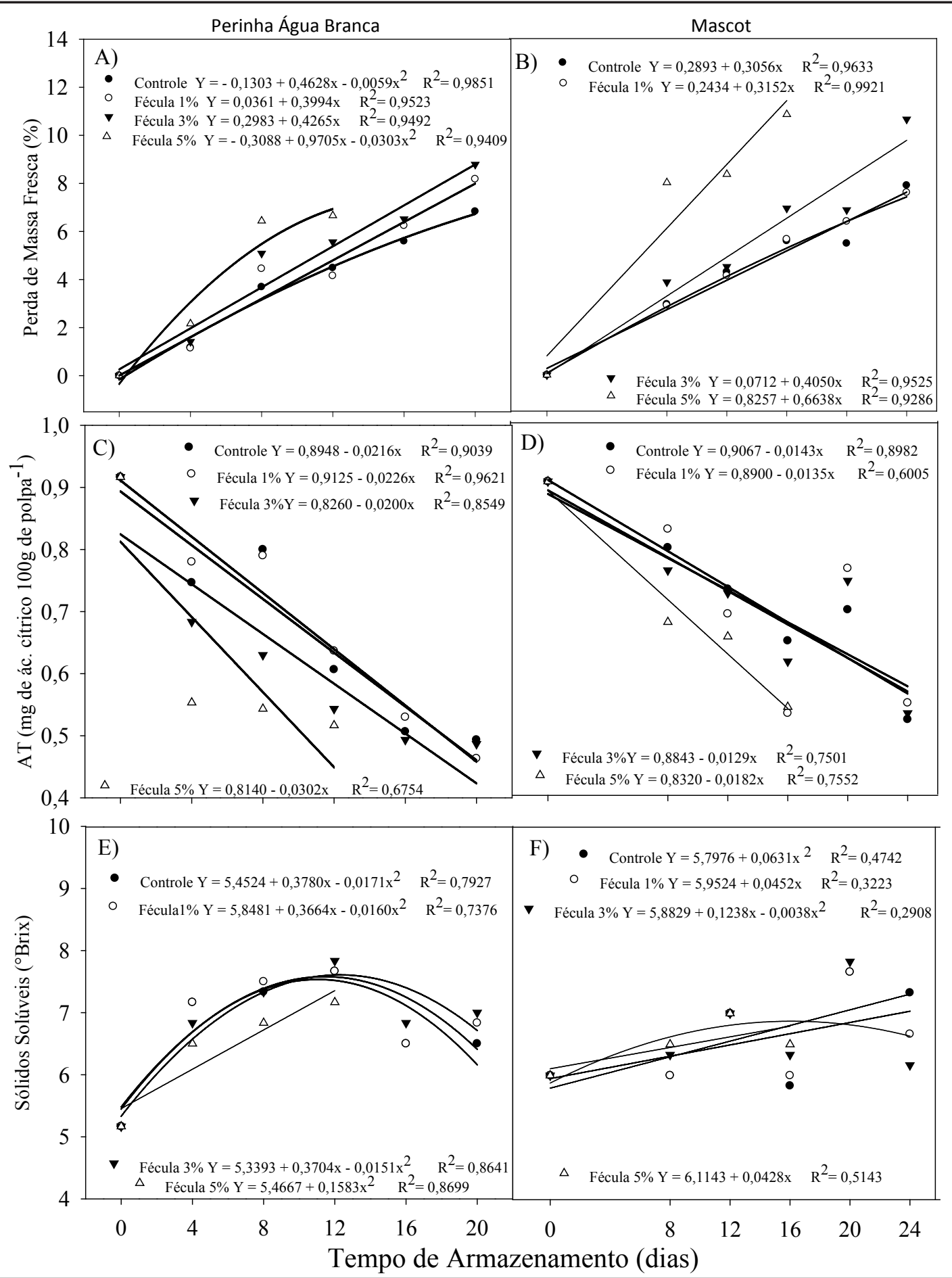

Figura 1. Perda de massa fresca (\%) (A e B), acidez titulável (AT) (C e D) e sólidos solúveis (E e F) de frutos de tomate cereja, cultivares Perinha Água Branca e Mascot, revestidos com película de fécula de mandioca em diferentes concentrações e armazenados em temperatura ambiente $\left(25 \pm 2^{\circ} \mathrm{C}\right) .{ }^{*} \mathrm{O}$ período de 4 dias na cultivar Mascot foi desconsiderado na discussão dos resultados \{weight loss (\%) (A and B), titratable acidity (AT) (C and D) and soluble solids (E and F) of cherry tomato fruits cvs. Perinha Água Branca and Mascot coated with cassava starch film at different concentrations and stored at room temperature $\left(25 \pm 2^{\circ} \mathrm{C}\right)$. *The 4-day period of cv. Mascot was neglected in the discussion of results\}. Seropédica, UFRRJ, 2013. 
desconsiderada na discussão devido à discrepâncias com os dados encontrados nas demais datas.

A película de fécula a 5\% demorou a secar e, após a secagem, causou danos aos frutos como extravasamento de líquidos na cicatriz peduncular e consequente desenvolvimento de fungos nessa região. Este efeito deve-se, provavelmente, à contração da película exercendo força mecânica e leve esmagamento dos frutos. Ainda, em alguns frutos esta película não revestiu adequadamente apresentando aspecto quebradiço, agravado pelo manuseio. Em outros, a espessa camada da película pode ter influenciado na adequada troca de gases do fruto com o ambiente e dessa forma afetado o processo normal de amadurecimento. Ainda, neste tratamento registrou-se alto índice de frutos

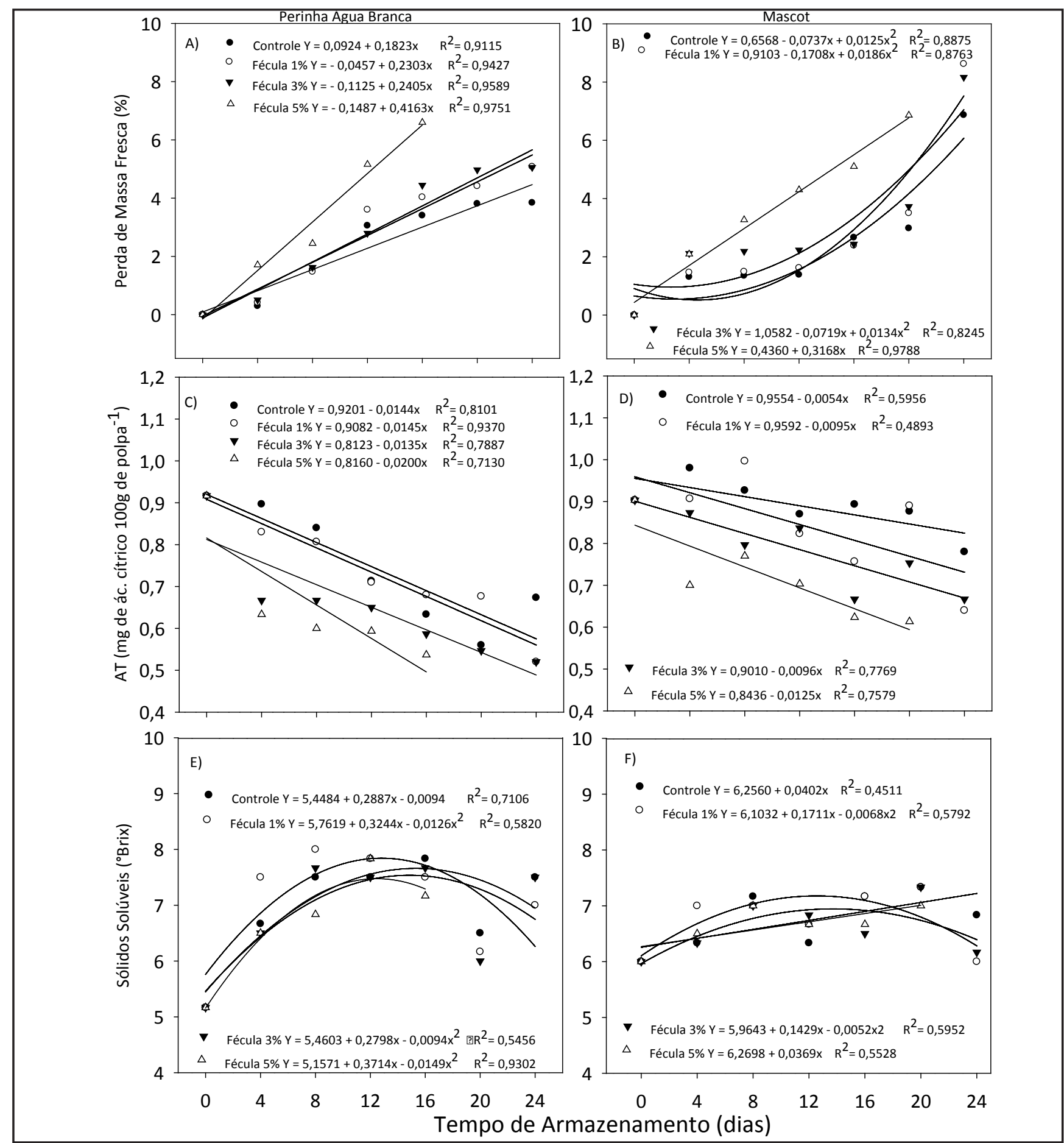

Figura 2. Perda de massa fresca (\%) (A e B), acidez titulável (AT) (C e D) e sólidos solúveis (E e F) de frutos de tomate cereja cultivares Perinha, Água Branca e Mascot, revestidos com película de fécula de mandioca em diferentes concentrações e armazenados em temperatura controlada $\left(12^{\circ} \mathrm{C}\right.$ e UR de $\left.90 \%\right)$ \{weight loss $(\%)$ (A and B), titratable acidity (AT) (C and D) and soluble solids (E and F) of cherry tomato fruits cvs. 'Perinha Água Branca' and Mascot coated with cassava starch film at different concentrations and stored under controlled temperature $\left(12^{\circ} \mathrm{C}\right.$ and 90\% RH) $\}$. Seropédica, UFRRJ, 2013. 
infectados por fungos diversos.

Perda de massa fresca - Todos os frutos das cultivares Perinha e Mascot apresentaram tendência à perda de massa fresca ao longo do tempo em todos os tratamentos, sendo os frutos revestidos com fécula $5 \%$ os com maiores perdas (Figuras 1A e 1B).

A partir de 20 dias, os frutos de 'Perinha' revestidos com fécula 1 e $3 \%$ apresentaram perdas de massa fresca maiores que 7\% (Figura 1A) enquanto que em frutos de 'Mascot' submetidos aos mesmos tratamentos, perdas equivalentes somente foram observadas aos
24 dias, inclusive no tratamento controle e no tratamento fécula $5 \%$ aos 8 dias (Figura 1B). De acordo com Chitarra \& Chitarra (2005), esses frutos seriam considerados impróprios para comercialização e consumo devido à sua grande perda de umidade, comprometendo inclusive sua aparência, no entanto, os frutos das cultivares trabalhadas se apresentavam visualmente com boa qualidade.

Para 'Perinha', as médias de perda de massa fresca no controle e nos frutos revestidos não diferiram estatisticamente. Na cv. Mascot a maior média de perda de massa fresca foi para fécula $5 \%$ seguido da concentração de $3 \%$. As menores médias ocorreram para o controle e fécula $1 \%$ que foram estatisticamente iguais entre si (Tabela 1), ou seja, os revestimentos mais concentrados foram os que proporcionaram maiores perdas de massa fresca.

Souza et al. (2009) observaram maiores perdas de massa fresca em berinjelas revestidas com fécula de mandioca em relação ao controle. Batista et al. (2007) encontraram maiores perdas de massa fresca em melões revestidos com fécula $3 \%$ a partir do $15^{\circ}$ dia de
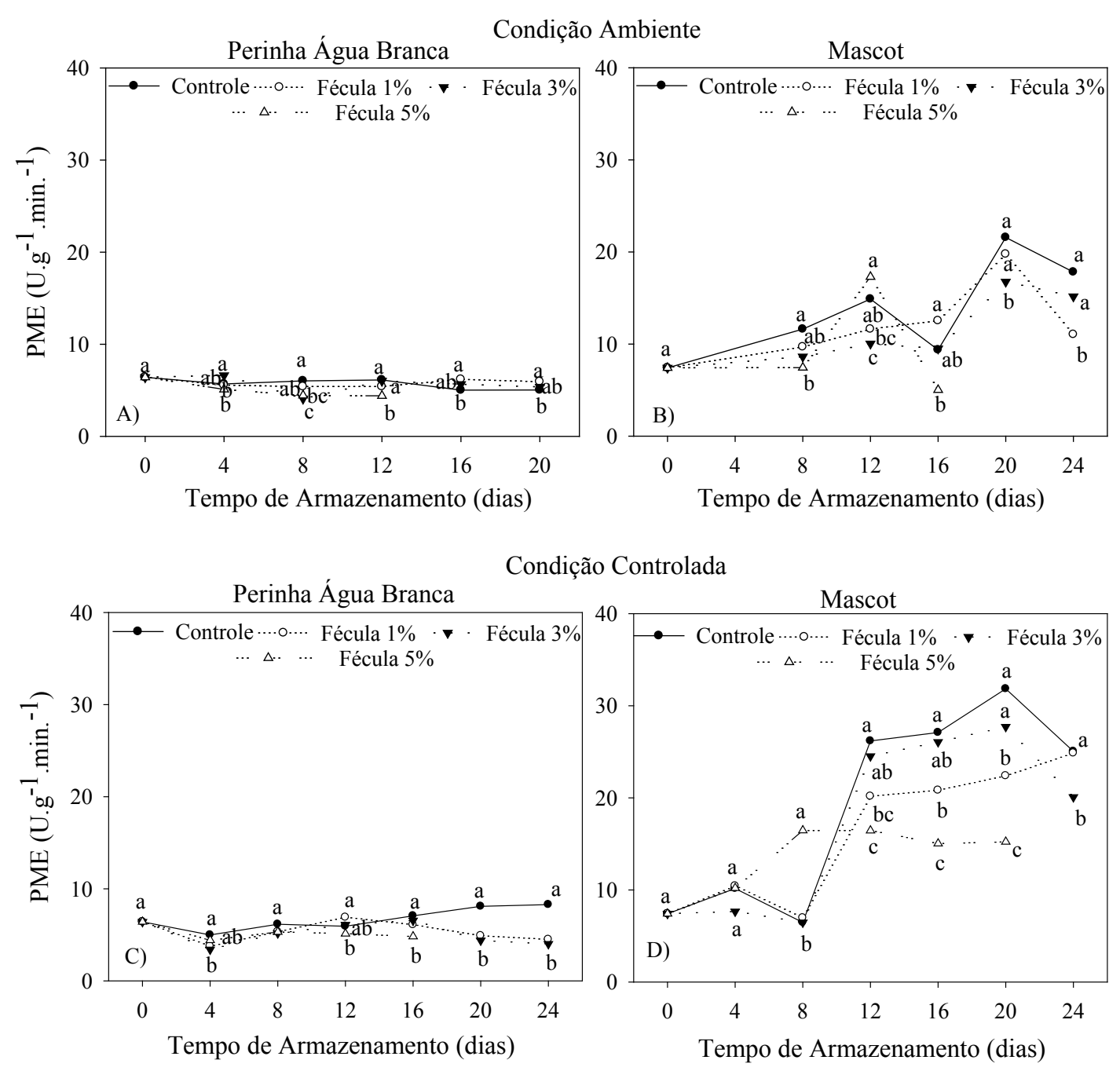

Figura 3. Atividade de pectinametilesterase (PME) em tomates cereja revestidos com diferentes concentrações de fécula de mandioca e armazenados em condições ambiente $\left(25 \pm 2^{\circ} \mathrm{C}\right)$ e controlada $\left(12^{\circ} \mathrm{C}\right.$ e UR de $\left.90 \%\right)$. A) 'Perinha Água Branca' e B) Mascot em condição ambiente; C) 'Perinha Água Branca' e D) 'Mascot' em condição controlada. As letras comparam os tratamentos dentro de cada tempo, sendo que letras iguais entre eles não se diferem significativamente pelo teste Tukey ( $<<0,05)$. O período de 4 dias na cultivar Mascot foi desconsiderado na discussão dos resultados \{pectinmethylesterase activity (PME) of cherry tomato fruits coated with different concentrations of cassava starch film and stored at room temperature $\left(25 \pm 2^{\circ} \mathrm{C}\right)$ and controlled temperature $\left(12^{\circ} \mathrm{C}\right.$ and UR $\left.90 \%\right)$. A) 'Perinha Água Branca' and B) 'Mascot' at room temperature C) 'Perinha Água Branca' and D) 'Mascot' in controlled temperature. The letters compare treatments within each time and the same letters between them do not differ significantly by Tukey’s test ( $\mathrm{p}<0,05)$. The 4-day period of cv. Mascot was neglected in the discussion of results\}. Seropédica, UFRRJ, 2013. 
armazenamento, o que pode ter ocorrido devido ao aparecimento de podridões na região peduncular dos frutos e a presença de sintomas de fermentação. Entretanto, bons resultados foram encontrados por Santos et al. (2011) para manga, onde o revestimento de fécula de mandioca controlou a perda de massa fresca ao longo do tempo nos frutos da cv. Tommy Atkins.

Além disso, durante o amadurecimento, os frutos sofrem mudanças em seus processos fisiológicos com o aumento da atividade respiratória, síntese de etileno e transpiração e, conseqüentemente, ocorre perda de massa fresca (Chitarra \& Chitarra, 2005). No presente trabalho observou-se que as películas em maiores concentrações (3 e 5\%) podem ter provocado com sua contração durante o período de secagem aumento da atividade respiratória, que também pode ter favorecido a perda de massa.

Comparando-se os tratamentos para as duas cultivares, verificou-se que as perdas de massa fresca nos frutos de 'Mascot' foram superiores que as observadas nos frutos de 'Perinha' nos tratamentos controle, fécula 3 e $5 \%$. Na concentração de $1 \%$ não foi observada diferença significativa entre as perdas nos frutos das duas cultivares (Tabela 1).

Acidez titulável - A acidez reduziu ao longo do armazenamento em todos os tratamentos para as duas cultivares. Para a cv. Perinha, os valores de acidez dos frutos controle e dos revestidos com fécula $1 \%$ foram próximos, e frutos com 3 e $5 \%$ foram menores (Figura 1C). O mesmo ocorreu na cv. Mascot, cujos valores de acidez do controle, féculas $1 \mathrm{e}$ $3 \%$ foram próximos quando comparados aos valores dos frutos revestidos com fécula 5\% que apresentaram tendência diferente dos demais tratamentos (Figura 1D). Isto sugere que as concentrações de fécula utilizadas não foram eficientes no controle do processo de amadurecimento, já que mostraram valores de acidez próximos ou menores que os do tratamento controle. Otoni et al. (2011), estudando revestimentos de 1, 3 e $5 \%$ em frutos de mamão, encontraram maiores valores de acidez em frutos com revestimento quando comparados ao controle, sugerindo que a fécula de mandioca reteve o amadurecimento por formar uma barreira semipermeável no fruto. Neste trabalho, não houve efeito de tratamento ou de cultivar sobre o valor médio de acidez dos frutos (Tabela 1).

Sólidos solúveis - Os sólidos solúveis dos frutos de 'Perinha' aumentaram até o $12^{\circ}$ dia em todos os tratamentos de revestimento, inclusive no controle, com posterior queda em seus valores. Os sólidos solúveis dos frutos revestidos com suspensão de fécula de mandioca $5 \%$ mantiveram tendência linear até a última avaliação. Os frutos revestidos com fécula a 3\% mantiveram valores mais altos a partir do $12^{\circ}$ dia quando comparado aos demais tratamentos (Figura 1E). No híbrido Mascot, observou-se tendência de incremento/aumento dos sólidos solúveis apesar da grande oscilação dos valores, sendo que para aqueles revestidos com fécula a $3 \%$ no $24^{\circ}$ dia houve redução (Figura 1F). Segundo Aroucha et al. (2012), este aumento do teor de sólidos solúveis está ligado ao processo bioquímico de amadurecimento, enquanto a queda pode estar ligada ao consumo dos próprios sólidos solúveis nos processos respiratórios (Hojo et al., 2009).

Não houve efeito de tratamento ou de cultivar sobre o valor médio de sólidos solúveis dos frutos (Tabela 1).

Tabela 1. Médias de perda da massa fresca, acidez titulável, sólidos solúveis, pectinametilesterase e relação sólidos solúveis com acidez titulável (SS/AT) em frutos de tomate cultivares Perinha Água Branca e Mascot, armazenados em condições ambiente com temperatura média de $25 \pm 2^{\circ} \mathrm{C}$ e em condições controladas $\left(12^{\circ} \mathrm{C}\right.$ e UR de $\left.90 \%\right)$ \{average loss of fresh weight, titratable acidity, soluble solids, pectinmethylesterase and soluble solids relation with titratable acidity of cherry tomato fruits cvs. 'Perinha Água Branca' and 'Mascot' stored at room temperature with average temperatures of $25 \pm 2{ }^{\circ} \mathrm{C}$ and under controlled conditions $\left(12^{\circ} \mathrm{C}\right.$ and $\left.\left.90 \% \mathrm{RH}\right)\right\}$. Seropédica, UFRRJ, 2013.

\begin{tabular}{|c|c|c|c|c|c|c|c|c|c|c|}
\hline \multirow[t]{3}{*}{ Tratamentos } & \multicolumn{2}{|c|}{$\begin{array}{l}\text { Perda de massa } \\
\text { fresca }(\%)\end{array}$} & \multicolumn{2}{|c|}{$\begin{array}{c}\text { Acidez titulável } \\
\text { (mg ác. cítrico/100g } \\
\text { de polpa) }\end{array}$} & \multicolumn{2}{|c|}{$\begin{array}{c}\text { Sólidos solúveis } \\
\quad\left({ }^{\circ} \text { Brix }\right)\end{array}$} & \multicolumn{2}{|c|}{$\begin{array}{c}\text { Atividade de } \\
\text { pectinametilesterase } \\
(\mathrm{U} / \mathrm{g} / \mathrm{min})\end{array}$} & \multicolumn{2}{|c|}{ SS/AT } \\
\hline & \multicolumn{10}{|c|}{$\overline{\text { Condição ambiente }\left(25 \pm 2^{\circ} \mathrm{C}\right)}$} \\
\hline & Perinha & Mascot & Perinha & Mascot & Perinha & Mascot & Perinha & Mascot & Perinha & Mascot \\
\hline Controle & $3,63 \mathrm{Ba}$ & $4,36 \mathrm{Ac}$ & $0,68 \mathrm{Aa}$ & $0,71 \mathrm{Aa}$ & $6,72 \mathrm{Aa}$ & $6,64 \mathrm{Aa}$ & $5,71 \mathrm{Ba}$ & $13,78 \mathrm{Aa}$ & $9,88 \mathrm{Aa}$ & $9,35 \mathrm{Aa}$ \\
\hline Fécula 1\% & $4,03 \mathrm{Aa}$ & $4,45 \mathrm{Ac}$ & $0,69 \mathrm{Aa}$ & $0,71 \mathrm{Aa}$ & $6,80 \mathrm{Aa}$ & $6,55 \mathrm{Aa}$ & $5,81 \mathrm{Ba}$ & $12,00 \mathrm{Aab}$ & $9,85 \mathrm{Aa}$ & $9,22 \mathrm{Aa}$ \\
\hline Fécula 3\% & $4,56 \mathrm{Ba}$ & $5,47 \mathrm{Ab}$ & $0,64 \mathrm{Aa}$ & $0,69 \mathrm{Aa}$ & $6,83 \mathrm{Aa}$ & 6,61Aa & $5,69 \mathrm{Ba}$ & $11,25 \mathrm{Abc}$ & $10,67 \mathrm{Aa}$ & $9,57 \mathrm{Ba}$ \\
\hline Fécula 5\% & $3,81 \mathrm{Ba}$ & $6,80 \mathrm{Aa}$ & $0,63 \mathrm{Aa}$ & $0,69 \mathrm{Aa}$ & $6,42 \mathrm{Aa}$ & $6,50 \mathrm{Aa}$ & $5,08 \mathrm{Ba}$ & $9,70 \mathrm{Ac}$ & $10,19 \mathrm{Aa}$ & $9,42 \mathrm{Aa}$ \\
\hline \multirow[t]{2}{*}{ CV (\%) } & \multicolumn{2}{|c|}{22,95} & \multicolumn{2}{|c|}{13,81} & \multicolumn{2}{|c|}{7,67} & \multicolumn{2}{|c|}{22,90} & \multicolumn{2}{|c|}{26,39} \\
\hline & \multicolumn{10}{|c|}{ Condição controlada $\left(12^{\circ} \mathrm{C}\right.$ e UR de $\left.90 \%\right)$} \\
\hline Controle & $2,28 \mathrm{Aa}$ & $2,36 \mathrm{Ab}$ & $0,75 \mathrm{Ba}$ & $0,89 \mathrm{Aa}$ & $6,93 \mathrm{Aa}$ & $6,74 \mathrm{Aa}$ & $6,70 \mathrm{Ba}$ & $19,17 \mathrm{Aa}$ & $9,24 \mathrm{Aa}$ & $7,57 \mathrm{Bb}$ \\
\hline Fécula 1\% & $2,72 \mathrm{Aa}$ & $2,73 \mathrm{Aab}$ & $0,73 \mathrm{Ba}$ & $0,84 \mathrm{Aab}$ & $7,08 \mathrm{Aa}$ & $6,74 \mathrm{Ba}$ & $5,41 \mathrm{Ba}$ & $16,14 \mathrm{Aab}$ & $9,70 \mathrm{Aa}$ & $8,02 \mathrm{Bab}$ \\
\hline Fécula 3\% & $2,77 \mathrm{Aa}$ & $2,98 \mathrm{Aab}$ & $0,65 \mathrm{Bb}$ & $0,78 \mathrm{Abc}$ & $6,83 \mathrm{Aa}$ & $6,59 \mathrm{Aa}$ & $5,15 \mathrm{Ba}$ & $17,13 \mathrm{Aab}$ & $10,51 \mathrm{Aa}$ & $8,45 \mathrm{Bab}$ \\
\hline Fécula 5\% & $3,18 \mathrm{Aa}$ & $3,60 \mathrm{Aa}$ & $0,66 \mathrm{Bb}$ & $0,72 \mathrm{Ac}$ & $6,73 \mathrm{Aa}$ & $6,64 \mathrm{Aa}$ & $5,21 \mathrm{Ba}$ & $13,45 \mathrm{Ab}$ & $10,20 \mathrm{Aa}$ & $9,22 \mathrm{Aa}$ \\
\hline $\mathrm{CV}(\%)$ & \multicolumn{2}{|c|}{41,64} & \multicolumn{2}{|c|}{11,58} & \multicolumn{2}{|c|}{7,91} & \multicolumn{2}{|c|}{40,50} & \multicolumn{2}{|c|}{22,34} \\
\hline
\end{tabular}

Médias seguidas de mesma letra minúscula na coluna e maiúscula na linha, não diferem significativamente pelo teste Tukey ( $\mathrm{p}<0,05)(\mathrm{means}$ followed by the same lowercase letter in the column and uppercase letter in the line do not differ significantly by Tukey's test at $5 \%$ ). 
Relação sólidos solúveis e acidez titulável (SS/AT) - Não houve diferença significativa nos tratamentos para ambas as cultivares. Quando comparadas as duas cultivares, somente fécula $3 \%$ se diferiu, sendo maior a relação na cultivar Perinha.

Armazenamento em temperatura e umidade relativa controlada $\left(12^{\circ} \mathrm{C}\right.$ e UR de 90\%) - As avaliações foram realizadas até o $24^{\circ}$ dia para os tratamentos controle, fécula a 1 e $3 \%$ enquanto que para fécula a $5 \%$ as avaliações ocorreram até o $16^{\circ}$ dia para 'Perinha' e $20^{\circ}$ dia para 'Mascot'. O tratamento de fécula a $5 \%$ afetou o processo normal de amadurecimento e favoreceu o desenvolvimento de podridões. Este resultado deve-se, provavelmente, ao revestimento mais espesso, o que pode provocar redução drástica nas concentrações de $\mathrm{O}_{2}$ e aumento no teor de $\mathrm{CO}_{2}$ levando à respiração anaeróbica e consequentemente a alterações fisiológicas dos frutos (Cruz et al., 2012).

Perda de massa fresca - Observou-se tendência ao longo do tempo do aumento da perda de massa fresca nos frutos das cultivares Perinha e Mascot (Figuras 2A e 2B). Na cv. Perinha, menores perdas de massa fresca ocorreram no controle quando comparado aos tratamentos com fécula, exceto no $12^{\circ}$ dia de avaliação quando os frutos tratados com fécula 3\% apresentaram perda de 2,80\% e os do controle de 3,06\% (Figura 2A). Quando foram comparadas as médias de perda de massa fresca (Tabela 1), estas não apresentavam diferenças significativas entre si, ou seja, os revestimentos de fécula tiveram o mesmo efeito do controle.

$\mathrm{Na} \mathrm{cv}$. Mascot (Figura 2B), os frutos dos tratamentos controle e os revestidos com fécula a $1 \%$ se mantiveram com valores próximos até o $16^{\circ}$ dia. A partir desta data, os valores de perda de massa em frutos revestidos com fécula $1 \%$ tenderam a ser maiores que o controle. Revestimentos de fécula 3 e 5\% tiverem as maiores perdas quando comparado ao controle, exceto no $16^{\circ} \mathrm{dia}$, quando a perda de massa fresca dos frutos com fécula 3\% foram inferiores.

Aos 24 dias, frutos da cv. Mascot revestidos com fécula a 1 e $3 \%$ tiveram perdas de massa fresca maiores que
7\%. De acordo com Chitarra \& Chitarra (2005), nesta condição os frutos estariam com sua qualidade afetada para a comercialização. No entanto, esses frutos estavam visualmente bons neste período.

Os frutos da cv. Mascot com revestimento de fécula 5\% tiveram a maior média de perda de massa, seguidos de 3 e $1 \%$, que não diferiram entre si e de fécula $5 \%$. Os frutos controle foram os que tiveram menor perda de massa fresca, porém foram estatisticamente semelhantes a fécula 1 e 3\% .Não houve diferença estatística para as médias de perda de massa fresca nos tratamentos quando comparadas as duas cultivares (Tabela 1).

Filmes formados por polissacarídeos, como fécula de mandioca, são eficientes no controle de gases como $\mathrm{O}_{2}$ e $\mathrm{CO}_{2}$ resultando na redução do processo respiratório (Hernández-Muñoz et al., 2008). Porém, são pouco eficientes no controle de perda de água o que pode explicar a perda de massa fresca em frutos revestidos com a fécula equiparados ao controle.

Acidez titulável - Em ambas cultivares, independente do tratamento, a acidez dos frutos decresceu com o tempo (Figuras 2C e 2D). Os frutos de 'Perinha' revestidos com fécula a $1 \%$ e controle se apresentaram mais ácidos que os de fécula 3 e $5 \%$, durante todo o período de armazenamento. Em 'Mascot' houve maior variação entre os valores de acidez nos tratamentos controle, fécula 1 e $3 \%$, sendo que fécula 5\% apresentou tendência de menor acidez (Figura 2D).

Os valores médios de acidez foram menores nos frutos de 'Perinha' revestidos com fécula 5 e 3\%, seguidos por frutos revestidos com fécula $1 \%$ e pelo controle (Tabela 1). Para 'Mascot', a acidez titulável apresentou grandes variações em função dos tratamentos com maiores valores nos frutos controle, seguido de fécula 1 e $3 \%$. O menor valor médio de acidez foi observado em fécula $5 \%$ quando comparado ao controle (Tabela 1).

Os valores médios de acidez titulável em todos os tratamentos de 'Mascot' foram superiores aos encontrados nos frutos da 'Perinha' submetidos aos mesmos tratamentos (Tabela 1). A acidez nos frutos indica a quantidade de ácidos orgânicos presentes nos frutos e é a principal característica que influencia no sabor (Nascimento et al., 2013).

Sólidos solúveis - $\mathrm{O}$ teor de sólidos solúveis apresentou valores iniciais baixos com acréscimo ao longo do tempo e posterior redução em todos os tratamentos para a cultivar Perinha, de modo muito semelhante (Figura 2E). O mesmo pode ser observado nos tomates da cultivar Mascot revestidos com fécula a 1 e $3 \%$. Os sólidos solúveis nos tratamentos controle e fécula a 5\% apresentaram crescimento linear (Figura 2F). Os valores para 'Perinha' (Figura 2E) aumentaram até o $16^{\circ}$ dia de armazenamento em todos os tratamentos, com posterior queda no $20^{\circ}$ dia e um aumento no $24^{\circ}$ dia. Este decréscimo nos sólidos solúveis para fécula $5 \%$ foi verificado no $16^{\circ}$ dia. Para a cv. Mascot, os teores de sólidos solúveis tiveram tendência de aumento ao longo do tempo com queda somente no último dia de avaliação ( $24^{\circ}$ dia) nos frutos revestidos por fécula $1 \mathrm{e}$ $3 \%$. Quando os frutos foram revestidos com fécula $5 \%$ ou no controle a tendência de crescimento manteve-se linear ao longo do tempo (Figura 2F).

Assim como neste trabalho, Nunes et al. (2004), utilizando película de fécula de mandioca em frutos de pêssego, observaram aumento nos teores de sólidos solúveis até o $6^{\circ}$ dia com posterior queda, sendo o aumento atribuído à perda de massa fresca que resulta em acúmulo de sólidos e à redução de açúcares devido ao consumo como substrato respiratório.

Comparando as duas cultivares, observou-se que o único tratamento que diferiu significativamente foi fécula $1 \%$, sendo o conteúdo de sólidos solúveis maiores para a cv. Perinha nesta concentração (Tabela 1).

Relação sólidos solúveis e acidez titulável (SS/AT) - Para a cultivar Perinha não houve diferença significativa nos tratamentos com fécula. Em 'Mascot', maior relação SS/AT foi obtida em frutos revestidos com fécula 5\%. Quando comparadas as duas cultivares, 'Perinha' apresentou maior relação $\mathrm{SS} / \mathrm{AT}$ nas concentrações de 0,1 e $3 \%$ de fécula em relação à 'Mascot'. Para fécula $5 \%$ as cultivares não apresentaram diferenças 
significativas.

Segundo Sobreira et al. (2010), a relação sólidos solúveis e acidez é um dos principais índices utilizados para a determinação do sabor em frutos, por isso, quanto menor a acidez melhor o sabor.

Pectinametilesterase (PME) - Para 'Perinha' (Figura 3A), os valores de PME para o tratamento controle e féculas 1 e $5 \%$ foram sempre menores que o obtido na avaliação inicial (0 dias). Frutos revestidos com fécula 3\% apresentaram atividade de PME aumentada aos 4 dias. A partir destas datas, a PME decresceu em relação ao valor inicial, mas com grandes oscilações ao longo do tempo, contudo as concentrações de $1 \%$ e $3 \%$ não diferiram do controle ou ficaram com valores acima, exceto aos 8 dias para fécula $3 \%$, que mostrou-se mais eficiente. Tomates revestidos com suspensão contendo fécula a 5\% apresentaram menor atividade de PME entre o $8^{\circ}$ e $12^{\circ}$ dia de avaliação, com maior retenção do amolecimento dos frutos quando comparado ao controle.

Para 'Mascot' (Figura 3B), os valores de PME aumentaram ao longo do tempo no controle e revestimentos de fécula 1 e $3 \%$ em relação ao valor de PME inicial. Fécula 5\% proporcionou aumento dessa atividade até o $12^{\circ}$ dia, havendo queda no $16^{\circ}$ dia, último dia de avaliação. Apesar do aumento ao longo do tempo, os menores valores de PME quando comparados ao controle foram encontrados aos 24 dias em frutos revestidos com fécula $1 \%$ e aos 8 e 12 dias, respectivamente, para fécula 5 e 3\%. Nos outros períodos avaliados, estas concentrações não diferiram significativamente do controle, indicando que não houve retenção do processo de amolecimento nos frutos.

Não houve diferença nos valores médios dos tratamentos em 'Perinha'. $\mathrm{Na}$ cv. Mascot, as médias da PME seguiram valores decrescentes de acordo com o aumento da concentração de fécula, contudo, féculas 3 e 5\% apresentaram menores valores de PME quando comparadas ao controle (Tabela 1). Essa menor atividade enzimática pode ser resultado de uma maior retenção do processo de amadurecimento dos frutos proporcionado por essas concentrações de fécula.

Os valores médios da PME na 'Mascot' foram superiores aos da 'Perinha' em todos os tratamentos (Tabela 1). Os frutos de 'Perinha' se apresentaram mais firmes mesmo com o amadurecimento, característica que pode estar associada à cultivar.

Segundo Resende et al. (2004), essas diferenças entre as duas cultivares podem ser explicadas pelo perfil de amadurecimento, onde as enzimas são liberadas pela parede celular de forma e em tempos diferentes, como também devido à natureza das substâncias pécticas e outros componentes da parede celular.

Os valores de PME encontrados neste trabalho estão acima dos encontrados por Resende et al. (2004) em tomates de mesa híbridos $\mathrm{F}_{1}$ experimentais do grupo multilocular. Porém, em outros trabalhos os resultados para PME estão acima do encontrado no presente estudo, como o realizado por Pires et al. (2009), no qual valores de PME para tomate de mesa híbrido 'Vênus' ficaram na faixa de 45 a $90 \mu \mathrm{mol} / \mathrm{g} / \mathrm{min}$ e Vilas Boas et al. (2000), com valores de PME na faixa de 35 a $40 \mu \mathrm{mol} / \mathrm{g} / \mathrm{min}$.

Para cv. Perinha (Figura 3C), a atividade da enzima PME aumentou a partir do $16^{\circ}$ dia nos tomates do tratamento controle, sendo maior aos 20 e 24 dias. Os tratamentos com féculas 1 e $3 \%$ não diferiram entre si e foram menores que o controle em todo período de armazenamento, o que pode ter contribuído para o retardo do amaciamento dos frutos. Em fécula 5\%, a atividade da enzima se manteve baixa durante o seu período de avaliação de 16 dias quando comparado aos demais tratamentos, resultando em frutos mais firmes.

Segundo Ali et al. (2004), as taxas de amolecimento variam com o tipo de fruto, sendo a PME responsável por catalisar a desesterificação da pectina e influenciar na ação de outras enzimas, como na criação de ambientes iônicos adequados ou ainda atuando no aumento da porosidade da parede, facilitando a ação de outras enzimas aos seus potenciais substratos. Isto amplia a relevância da ação de PME no amaciamento dos frutos.

Para 'Mascot' (Figura 3D), apesar da oscilação nos valores da atividade de PME, estes aumentaram do início até o $20^{\circ}$ dia de armazenamento. Menor atividade foi observada aos 8 dias nos frutos controle, fécula 1 e $3 \%$. Tomates revestidos com fécula a 5\% apresentaram os menores valores de atividade enzimática comparado aos demais tratamentos do $12^{\circ}$ dia ao $20^{\circ}$ dia. Apesar de este tratamento ter sido encerrado aos 20 dias, o revestimento com fécula a 5\% apresentou menores valores de PME quando comparado aos demais, resultando em frutos com menor grau de amolecimento.

Os valores médios de PME em 'Perinha' não diferiram em função do tratamento (Tabela 1). Em tomates 'Mascot' foram observadas maiores médias da atividade enzimática obtidas para o controle, em relação a frutos revestidos com fécula 5\%. Este revestimento reteve o amadurecimento proporcionando frutos mais firmes, característica essa fundamental para a comercialização. Tomates revestidos com filmes à base de fécula a 1 e $3 \%$ apresentaram valores intermediários e não apresentaram diferenças significativas entre si.

Os valores médios de PME em 'Mascot' foram superiores à 'Perinha' em todos os tratamentos (Tabela 1). Essas diferenças na atividade enzimática provavelmente estão relacionadas com a característica genética de cada cultivar.

Os revestimentos não apresentaram diferenças significativas nas características avaliadas para as duas cultivares em temperatura ambiente e controlada. Contudo, alguns resultados foram mais expressivos em características isoladas (Tabela 1). Em temperatura ambiente, quando se compara o efeito dos tratamentos para cada cultivar, a perda de massa fresca em 'Mascot' foi maior em frutos revestidos com féculas a 3 e a $5 \%$. Ainda em 'Mascot' estes revestimentos proporcionaram menor atividade de pectinametilesterase, retardando o amadurecimento, contudo o revestimento de fécula a $5 \%$ proporcionou baixa longevidade pós-colheita, por isso o revestimento de $3 \%$ pode ser considerado mais eficaz, com menor atividade enzimática, em relação ao controle. Em temperatura controlada a acidez titulável foi menor para revestimento de 3 e $5 \%$ em 'Mascot' e 'Perinha', mas a longe- 
vidade pós-colheita também foi menor para $5 \%$, o que torna o revestimento $3 \%$ melhor para essa característica. A atividade de PME foi menor em fécula 5\% para 'Mascot'. Frutos revestidos com fécula $1 \%$ se assemelharam ao controle (frutos não revestidos) durante quase todo período experimental em ambas as temperaturas. As duas cultivares apresentaram comportamentos distintos para os revestimentos de fécula utilizados, contudo o revestimento de frutos com fécula $3 \%$ pode ser considerado o mais eficaz, pois manteve algumas características de frutos não revestidos mas com destaque para outros parâmetros de qualidade como menor acidez e menor atividade de pectinametilesterase, retardando o amadurecimento.

Quando se compara as cultivares, em temperatura ambiente e controlada, frutos de 'Mascot' apresentaram maiores teores médios de acidez independente do revestimento. A atividade de pectinametilesterase em 'Perinha' foi menor que 'Mascot' em todos os tratamentos com fécula. Isso é uma indicação de que esta cultivar tende a apresentar maior firmeza natural dos frutos, evidenciando que a aplicação de fécula pode não apresentar eficiência para este componente de qualidade.

\section{AGRADECIMENTOS}

Ao curso de Pós-Graduação em Fitotecnia da Universidade Federal Rural do Rio de Janeiro. À CAPES e CNPq pelo apoio financeiro.

\section{REFERÊNCIAS}

ALI ZM; CHIN LH; LAZAN H. 2004. A comparative study on wall degrading enzymes, pectin modifications and softening during ripening of selected tropical fruits. Plant Science 167: 317-327.

AROUCHA EMM; SOUZA CSM; SOUZA AED; FERREIRA RMA; FILHO JCA. 2012. Qualidade pós-colheita da cajarana em diferentes estádios de maturação durante armazenamento refrigerado. Revista Brasileira de Fruticultura 34: 391-399.

BATISTA PF; SANTOS AEO; PIRES MMML; DANTAS BF; PEIXOTO AR; ARAGÃO CA. 2007. Utilização de filmes plásticos e comestíveis na conservação pós-colheita de melão amarelo. Horticultura Brasileira 25: 572-576.
BRASIL. Ministério da Agricultura do Abastecimento e da Reforma Agrária. 1995. Portaria $\mathrm{n}^{\circ} 553$ de 30 de agosto de 1995. Dispõe sobre a norma de identidade, qualidade, acondicionamento e embalagem do tomate in natura, para fins de comercialização e revoga as especificações de identidade, qualidade, acondicionamento e embalagem do tomate estabelecidas pela Portaria $n^{\circ} 76$, de 25 de fevereiro de 1975. Diário Oficial da República Federativa do Brasil, Brasília.

CASA J; EVANGELISTA RM. 2009. Influência das épocas de colheita na qualidade de tomate cultivado em sistemas alternativos. Semina: Ciências Agrárias, 30: 1101-1108.

CASTRICINI A. 2009. Aplicação de revestimentos comestiveis para conservação de mamões (Carica papaya) 'Golden'. Rio de Janeiro: UFRRJ. 117p. (Tese doutorado).

CEREDA MP; BERTOLLINI AC; EVANGELISTA RM. 1992. Uso do amido em substituição às ceras na elaboração de "películas" na conservação pós-colheita de frutas e hortaliças: estabelecimento de curvas de secagem. IN: CONGRESSO BRASILEIRO DE MANDIOCA, 7. Anais... Recife. p.107.

CHITARRA MLF; CHITARRA AB. 2005. Póscolheita de frutos e hortaliças: Fisiologia e Manuseio. Lavras: UFLA. 785p.

CRUZ MM; LINS SRO; OLIVEIRA SMA; BARBOSA MAG. 2012. Efeito de óleos essenciais e revestimentos comestíveis sobre podridões pós-colheita em manga, cv. Kent. Revista Caatinga 25: 1-6.

DAMASCENO S; OLIVEIRA PVS; MORO E; MACEDO JUNIOR EK; LOPES MC; VICENTINI NM. 2003. Efeito da aplicação de película de fécula de mandioca na conservação pós-colheita de tomate. Ciência e Tecnologia de Alimentos 23: 377-380.

FERREIRA SMR. 2004. Características de qualidade do tomate de mesa (Lycopersicon esculentum) cultivado nos sistemas convencional e orgânico comercializado na região metropolitana de Curitiba. Curitiba: UFPR. 231p. (Tese doutorado).

GALLO JAQ; DEBEAUFORTF; CALLEGARIM F; VOILLEY A. 2000. Lipid hydrophobicity, physical state and distribution effects on the properties of emulsion-based edible films. Journal of Membrane Science 180: 37-46.

HENRIQUE CM. 1999. Utilização do ethephon e da película de fécula de mandioca na conservação pós-colheita de limão siciliano (Citrus limon). São Paulo: UNESP-Botucatu. 161p. (Tese mestrado).

HERNÁNDEZ-MUÑOZ P; ALMENAR E; VALLE VD; VELEZ D; GAVARA R. 2008. Effect of chitosan coating combined with postharvest calcium treatment on strawberry (Fragaria X ananassa) quality during refrigerated storage. Food Chemistry 110: 428-435.

HOJO ETD; ABREU CMP; ASMAR SA; HOJO RH; CÔRREA AD; VILAS BOAS EVD. 2009. Avaliação da qualidade de mangas 'Palmer' tratadas com 1-metilciclopropeno armazenadas sob refrigeração e condição ambiente. Revista Brasileira de Fruticultura 31: $28-38$

HULTIN HO; SAM B; BULGER J. 1966. Pectinmethylesterase of the banana: purification and properties. Journal of Food Science 31: 320-327.
IAL. 1987. Normas analíticas do Instituto Adolfo Lutz: Métodos químicos e fisicos de análise de alimentos. 3 ed. São Paulo.

IBGE. 2012. Levantamento sistemático da produção agrícola: pesquisa mensal de previsão e acompanhamento das safras agrícolas no ano civil. Rio de Janeiro. 88p.

LEMOS OL; REBOUÇAS TNH; JOSÉ ARS; VILA MTR; SILVA KS; SILVA DS; BARRETO APP; BOMFIM MP. 2008. Conservação do pimentão "Magali" em duas condições de armazenamento associada à atmosfera modificada. Magistra 20: 06-15.

NASCIMENTO AR; JÚNIOR MSS; CALIARI M; FERNANDES PM; RODRIGUES JPM; CARVALHO WT. 2013. Qualidade de tomates de mesa cultivados em sistema orgânico e convencional no estado de Goiás. Horticultura Brasileira 31: 628-635.

NUNES EE; VILAS BOAS BM; CARVALHO GL; SIQUEIRA HH; LIMA LCO. 2004. Vida útil de pêssegos 'Aurora 2' armazenados sob atmosfera modificada e refrigeração. Revista Brasileira de Fruticultura 26: 438-440.

OTONI BS; MOTA WF; DIAS TC; MIZOBUTSI GP; SANTOS MGP. 2011. Aplicação de películas de fécula de mandioca na conservação pós-colheita de mamão. Revista Brasileira de Armazenamento 36: 164-170.

PIRES CRF; LIMA LCO; VILAS BOAS EVB; ALVES RR. 2009. Qualidade textural de tomates cultivados em substratos orgânicos submetidos à aplicação de substâncias húmicas. Pesquisa Agropecuária Brasileira 44: $1467-1472$.

RATNER A; GOREN R; MONSELINE SP. 1969. Activity of pectin esterase and cellulose in the abscission zone of citrus leaf explants. Plant Physiology 44: 1717-1723.

RESENDE JM; CHITARRA MIF; MALUF WR; CHITARRAAB; SAGGIN JUNIOR OJ. 2004. Atividade de enzimas pectinametilesterase e poligalacturonase durante o amadurecimento de tomates do grupo multilocular. Horticultura Brasileira 22: 206-212.

SANTOS AEO; ASSIS JS; BERBET PA; SANTOS OO; BATISTA PF; GRAVINA GA. 2011. Influência de biofilmes de fécula de mandioca e amido de milho na qualidade póscolheita de mangas 'Tommy Atkins'. Revista Brasileira Ciências Agrárias 6: 508-513.

SOBREIRA FM; SOBREIRA FM; ALMEIDA GD; COELHO RI; RODRIGUES R; MATTA FP. 2010. Qualidade de sabor de tomates dos tipos salada e cereja e sua relação com caracteres morfoagronômicos dos frutos. Ciência e Agrotecnologia 34: 1015-1023.

SOUZA PA; AROUCHA EMM; SOUZA AED; COSTA ARFC; FERREIRA GS; BEZERRA NETO F. 2009. Conservação pós-colheita de berinjela com revestimentos de fécula de mandioca ou filme de PVC. Brasileira Horticultura 27: 235-239.

VILA MTR. 2004. Qualidade pós-colheita de goiabas 'Pedro Sato' armazenadas sob refrigeração e atmosfera modificada por biofilme de fécula de mandioca. Lavras: UFLA. 66p. (Tese mestrado).

VILAS BOAS EV; CHITARRA AB; MALUF WR; CHITARRA MIF. 2000. Modificações texturais de tomates heterozigotos no loco alcobaça. Pesquisa Agropecuária Brasileira 35: 1447-1453. 